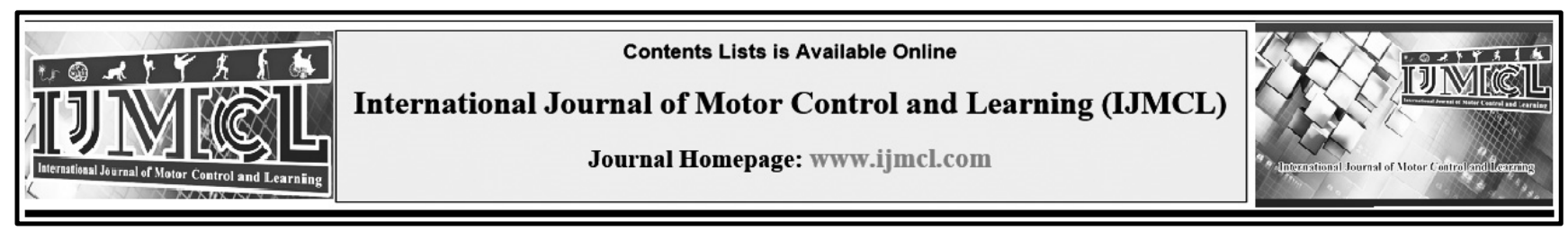

\title{
The Effect of Instructional Language Types on Perceived Choice, and the Learning of a Sports Skill
}

\author{
Saeed Arsham ${ }^{\mathrm{a}^{*}}$, Malihe Sarabandi ${ }^{\mathrm{b}}$, Fatemeh Ghenaatian ${ }^{\mathrm{c}}$
}

a Assistant Professor, Department of Motor Behavior, Kharazmi University, Tehran, Iran.

${ }^{\mathrm{b}} \mathrm{Ph}$.D. Student in Motor Behavior at Ferdowsi University of Mashhad \& Instructor, Department of Sports Sciences, Faculty Literature and Human Sciences, University of Zabol, Sistan and Baluchestan, Iran.

${ }^{\mathrm{c}}$ Faculty Member of Farhangian University, Shiraz, Iran.

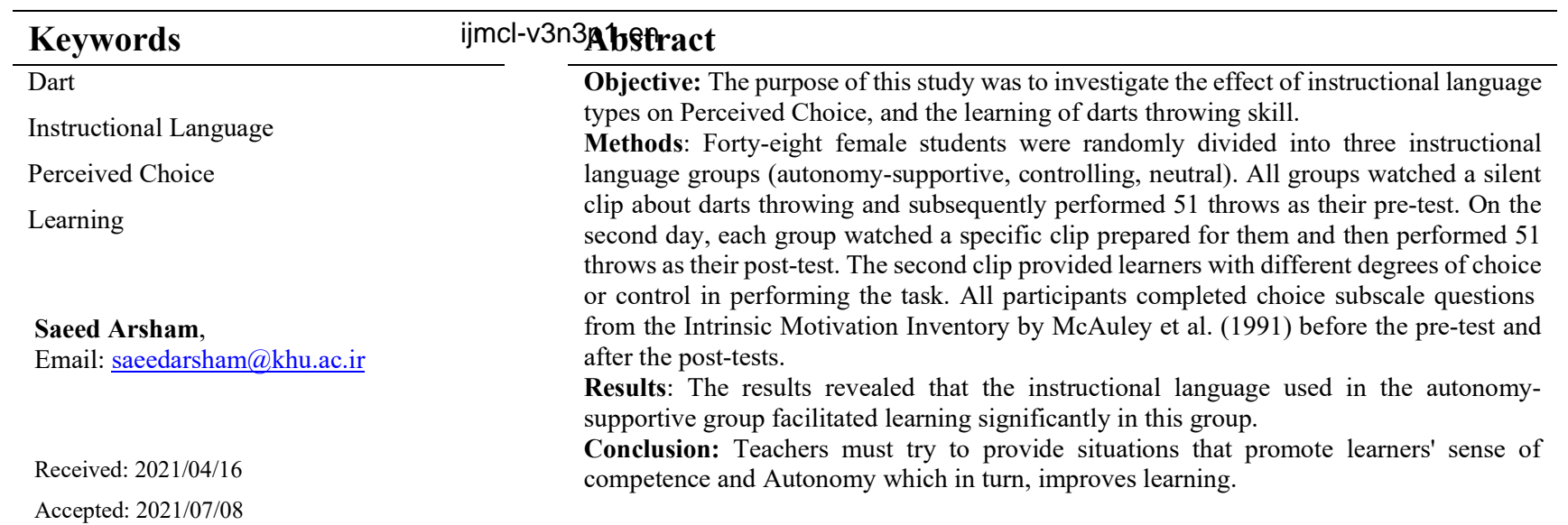

\section{Introduction}

In recent years, some studies in the field of motor learning have examined the benefits of giving the learner control on part of the instruction set as a way to accelerate the acquisition of skills.

Overall, research in this area has shown that giving the learner the right to choose during the task has a positive effect on skill learning (compared to the absence of choice) (Wulf, 2007). One of the theories in the field of motor learning studies is Self-Determination Theory which can provide information about exercising control over the practice setting by the learner. According to part of the motivational Self-Determination Theory, there are three basic psychological needs: "autonomy", "competence", and "relatedness" (Sanli et al., 2013). Autonomy refers to the need for individuals to control or actively participate in determining activities. Allowing individuals to exercise control over their surroundings (self-control) may not only satisfy a basic psychological need but may also be a biological requirement (Lemos et al., 2017). It seems that learning significantly improves by reinforcing learners' need for autonomy, even though which variable the learners are free to choose or whether the choice has been directly related to the task at hand (Hooyman et al., 2014). Therefore, it is important to consider how 
instructional guidelines can enhance performance and learning. Accordingly, this study has attempted to investigate the relationship between SelfDetermination Theory and self-control practice setting to facilitate motor learning. A key point in providing coaching instruction is the communicative language (expression) that is used to this aim. This language has been experimentally modified in research, based on the way tasks are presented and the way people are monitored (De Muynck et al., 2017). The type of language used by the coaches during instruction refers to a particular method that the coach uses to motivate and engage learners in learning activities. The instructional language can be conceived of as a bipolar axis which on the one end there is the "controlling style", the "neutral style" stands in the middle and the "autonomy-supportive style" is on its other end (Deci et al., 1981). In the "controlling style", the coaches pressure athletes to think, feel, and act in the prescribed ways. In contrast, the "autonomysupportive" style identifies, trains, and creates intrinsic motivation resources to enhance athletes' sense of will (De Muynck et al., 2017). Neurological research indicates that manipulation of instructional language modifies motor learning (Kühn et al., 2008) whose positive effect is associated with the secretion of serotonin. On the other hand, the negative effect increases the autonomy-supportive activities to neutralize or replace negative thoughts and feelings leading to reassigning information resources and decreased learning (Schmader et al., 2008). In research done by Reeve and Tseng (2011), the controlling expression (in contrast to the autonomy-supportive style) created stress which could be detected from the cortisol level. Therefore, it is likely that the selfregulatory attempts to control negative emotional reactions have distracted the individual's attention from the task and thus reduced learning (Reeve \& Tseng, 2011). In the present research, the dartthrowing task is used. In such tasks, planning for motion should be carried out quickly and before it. It seems that quick decision-making is more likely to hinder self-regulation processes in the individual (Hooyman et al., 2014), while it is possible that in the long-term tasks where the subject has the time to examine and regulate his/her performance, focus on body movements increases leading to disruption in self-regulation processes in the learning process. Thus, it is likely that the type of task affects the impact of motivational factors on learning. In another study, participants in the two groups, one of which having the choice to produce force, were asked to produce the maximum possible force using a dynamometer. Maximum possible force during the exercises reduced significantly in the control group while participants of the "choice group" were able to maintain the maximum force produced in the exercise. Researchers interpreted the findings as evidence that reinforcing one's autonomy enhances movement efficiency (Iwatsuki et al., 2017). Hooyman et al. (2014) also researched the effect of instructional language on instructing bowling (cricket) tasks to three groups. The results showed that the satisfactory effect of "choice" may not only improve the participant's performance on the next task but also directly affects learning through consolidation of motor memory (Hooyman et al., 2014). It is noteworthy 
that in socio-psychological studies, research has been limited to identifying the intrinsic relationships among different variables without directly measuring performance or learning (Hooyman et al., 2014). Therefore, this study tries to measure learning followed by giving learners the right to choose. In the above research, a lot of explanation has been provided for the impact of improving learning following reinforcement of the learners' need for autonomy. Many of these studies have been linked to deeper information processing resulting from self-control (Chen \& Singer, 1992; Leiker et al., 2016). In contrast to what was said above, Wulf \& Lewthwaite (2016) state that the results indicating the positive effects of the right to choose, even optionally (Wulf \& Lewthwaite, 2016), or the autonomy-supportive instructional language (compare with the authoritative language) (Hooyman et al., 2014) on learning show that information processing is not the fundamental reason behind this effect (Wulf \& Lewthwaite, 2016). According to Wulf \& Lewthwaite's (2016) OPTIMAL Theory, by creating a sense of agency, the learner's autonomy strikes a balance among thoughts, attention, motivation, and neuromuscular activity so that the performer achieves his/her goals. These researchers suggest that the pairing of goals and behaviors may lead to the establishment of effective neural connections that facilitate learning and is effective in memory consolidation by making dopamine available (Wulf \& Lewthwaite, 2016). In addition, other research indicates that the perception of autonomy leads to changes included in the structural and functional connections of the nerves. Effective structural connections in the brain regions provide the basis for the establishment of functional connections through all brain networks (Wulf \& Lewthwaite, 2016). The existence of such connections seems to be a sign of skillful performance (Kim et al., 2014; Li et al., 2015). As a result, it is necessary to carry out research using learning criteria to evaluate the effect of choice. Accordingly, other measures, such as improving the learner's expectations to implement and support the learner's autonomy, may be used as motivational variables to facilitate the learner's performance (Chua et al., 2018). Therefore, based on the above explanations, there is a need for more extensive research to find areas for improvement of learning. In this regard, the present study seeks to answer the following questions: do the conditions in which the task is taught affect learning? Will instruction that gives the learner a certain degree of choice on how to perform a task leads to more effective learning compared to prescribed instruction that leaves no room for choice or even neutral instruction?

\section{Method}

This study uses a quasi-experimental methodology and adopts a quantitative approach; based on the research objectives, it is an applied study. The statistical population of the study consists of 300 undergraduate female students aged 18-23 who were studying at Farhangian University of Shiraz during the academic year 2017-18. Subjects who met the requirements for entering the test were randomly assigned into 3 groups. The sample size was 16 for each group. Using the demographic characteristics questionnaire, the 
criteria for entering the test included lack of experience in dart-throwing, right-handedness, no history of brain injury, lack of visual system damage, not using alcohol, cigarettes, psychotropic and hormonal drugs are studied as self-report. The Beck's Depression Inventory was used to screen subjects for depression and the Spielberger's StateTrait Anxiety Inventory was used to exclude subjects with trait and state anxiety as criteria to enter the test (Liu et al., 2008).

\section{Procedure}

Subjects who met the criteria to enter the test completed a written consent and were asked to cooperate with the researcher for two days of study and to be present at the dart club at 8 am. 48 subjects were randomly assigned into three groups: autonomy-supportive, controlling, and neutral. At the beginning of the study, a dart-throwing skill training film was played for each participant separately. Participants watched this video clip for 25 seconds with the sound off. The first film was the same for all groups. Since the participants had no experience in dart-throwing, the silent clip was intended only to familiarize participants with how to hold the dart and throw it. Subjects then did 17 rounds (51 throws) as a pre-test and the coordinates of the throws were recorded in centimeters. Twenty-four hours later, all subjects were present at the dart club at 8 a.m. to participate in the posttest. On this day, three instructional videos were shown with three different instructional language types (each with its instructional language). The duration of the instructional clips in the three groups was approximately three minutes. No external feedback was provided to participants to minimize interaction with the experimenter and to maximize instructional language effectiveness. The film's instructional language for the autonomysupportive group was inviting. For example, phrases like "I suggest", "you can" were used in dart training. In contrast, the instructional language of the controlling style was authoritative. For example, phrases like "you should", "if you don't ..., then ..." were used. Thereafter, each group performed 17 rounds (51 throws) as a post-test and again the coordinates of each throw were recorded. Before the pre-test and after the post-test, all subjects completed the subscale "Perceived Choice" of McAuley et al.'s (1991) Intrinsic Motivation Inventory to measure "choice" concerning the type of instructional language (McAuley et al., 1991). It should be noted that the number of attempts in the first and second days of tests was set according to Hooyman et al.'s (2014) and Lemos et al.'s (2017) studies (Hooyman et al., 2014; Lemos et al., 2017).

The method of calculating the scores was to manually record the coordinates of the distance between the throwing point and the center of the dart (points " $x$ " and " $y$ " of each throw) in centimeters; then, these points were inserted in the following two formulas to obtain the accuracy of each participant's performance. The radial error was calculated from the formula: $\mathrm{RE}=\left(x^{2}+\right.$ $\left.y^{2}\right)^{1 / 2}$. " $\mathrm{x}$ " and " $y$ " are coordinates of each throw along the horizontal and vertical axis, and RE is the radial error in each throw. The two-dimensional variable error formula is as follows: 


$$
\mathrm{VE}=\left\{\left(\frac{1}{K}\right) \sum_{i=1}^{k}\left[\left(x_{i}-x_{c}\right)^{2}+\left(y_{i}-y_{c}\right)^{2}\right]\right\}^{1 / 2}
$$

In which " $\mathrm{K}$ " is the number of attempts, i a particular attempt, " $\mathrm{x}_{\mathrm{c}}$ " and " $\mathrm{y}_{\mathrm{c}}$ " are the mean distance from " $x$ " and " $y$ ", respectively, and VE is a two-dimensional variable error (Hancock et al., 1995). In this study, radial error (deviation from the target) and 2-dimensional variable error (degree of homogeneity of throws) were considered as criteria for the accuracy of an individual's performance and learning. In the present study, one of the subscales of McAuley et al.'s (1991) Intrinsic Motivation Inventory i.e., "Perceived Choice (PC)" was used (McAuley et al., 1991). The inventory consists of 45 items and gauges 6 subscales: Interest / Enjoyment, Perceived Competence, Effort, Value / Usefulness, Pressure / Tension, Relatedness, and Perceived Choice, thus producing 6 separate scores from these subscales. This inventory is rated on a Likert-type scale. The answers range from 1 (not right at all) to 7 (totally wrong). Also, 16 items of this inventory are scored in reverse. The lowest gained score is 45 and the highest is 315 . The reliability coefficient of the subscale "perceived choice" using Cronbach's alpha in the present study was 0.75 . It is noteworthy that in previous studies many researchers have used only subscales related to their research questions and no negative effects of excluding some subscales have been reported (Sanli et al., 2013).

In this study, the standard dartboard was used in a circular form made from Papier-mâché with a diameter of $453 \pm 3 \mathrm{~mm}$ and $37 \mathrm{~mm}$ thickness. 15$\mathrm{cm}$-long dart metal arrows weighing 25 grams were used for throwing. The distance from the center of the plate to the ground was $1.73 \mathrm{~m}$, according to international dart laws, and the subjects threw from a distance of $2.37 \mathrm{~m}$.

Descriptive statistics (mean and standard deviation) were used to describe the data. Multivariate Analysis of Covariance (MANCOVA) and Bonferroni post hoc tests were used to test the research hypothesis. Data were analyzed using SPSS software version 22 and the significance level was set to be $\mathrm{P} \leq 0.05$ for all the variables.

\section{Results}

Table 1 shows the mean and standard deviation of the three research variables in pre-test and posttest.

Table 1: Means and standard deviations of the three groups in the pre-and post-tests.

\begin{tabular}{lllllll}
\hline \multirow{2}{*}{$\begin{array}{l}\text { Group } \\
\text { Variable }\end{array}$} & \multicolumn{2}{c}{$\begin{array}{l}\text { Autonomy-supportive } \\
\text { pre-test }\end{array}$} & post-test & $\begin{array}{l}\text { Controller } \\
\text { pre-test }\end{array}$ & post-test & $\begin{array}{l}\text { Neutral } \\
\text { pre-test }\end{array}$ \\
\hline RE & $18.03 \pm 3.11$ & $12.95 \pm 3.12$ & $18.07 \pm 4.43$ & $16.98 \pm 4.44$ & $17.40 \pm 3.10$ & $16.40 \pm 3.67$ \\
VE & $17.67 \pm 1.78$ & $14.02 \pm 2.27$ & $17.25 \pm 1.85$ & $16.67 \pm 2.80$ & $17.22 \pm 1.96$ & $16.06 \pm 2.97$ \\
PC & $40.75 \pm 4.48$ & $47 \pm 2.13$ & $40.94 \pm 4.61$ & $41.81 \pm 3.31$ & $40.50 \pm 7.15$ & $40.87 \pm 9.55$ \\
\hline
\end{tabular}

RE: Radial Error, VE: Variable Error, and PC: Perceived Choice. 
The hypothesis of this study was as follows: The type of the instructor's instructional language has a significant effect on perceived choice and learning. Multivariate Analysis of Covariance (MANCOVA) was used to test this hypothesis. The results of the Box test were not statistically significant $(\mathrm{P}>0.05$ and $\mathrm{F}=1.25)$, which means that the covariance matrix homogeneity is the default confirmation.

Table 2: Test of Homogeneity of Variances

\begin{tabular}{lllll}
\hline Variable & F & DF1 & DF2 & $P$-value \\
\hline RE post-test & 0.37 & 2 & 45 & 0.69 \\
VE post-test & 3.12 & 2 & 45 & 0.06 \\
PC post-test & 1.84 & 2 & 45 & 0.17 \\
\hline
\end{tabular}

Table 2 shows that Levene's test is not significant in the post-test of the research variables important because it confirms the reliability of and therefore the variances are equal. This is subsequent results.

Table 3: MANCOVA Results for Dependent Variables.

\begin{tabular}{llllll}
\hline Effect & Stat & Value & $\mathbf{F}$ & $\boldsymbol{P}$-value & $\boldsymbol{\eta}^{\mathbf{2}}$ \\
\hline \multirow{6}{*}{ Group } & Pillai Trace & 0.43 & 3.70 & 0.003 & 0.21 \\
& Wilks Lambda & 0.59 & 4.07 & 0.001 & 0.23 \\
& Hotelling's Trace & 0.68 & 4.42 & 0.001 & 0.25 \\
& Roy's Largest Root & 0.65 & 8.83 & 0.001 & 0.39 \\
\hline
\end{tabular}

Considering the $\mathrm{F}$ value and the significance level of MANCOVA (Table 3), it can be seen that the linear combination of variables is significantly different for belonging to groups. The magnitude of the effect of the Eta Squared test shows that the type of instructional language has a significant effect on perceived choice and learning.

Table 4: ANCOVA results for the effects of the instructional language on perceived choice and learning.

\begin{tabular}{|c|c|c|c|c|c|c|}
\hline Variable & Type III Sum of Squares & DF & Mean Square & $\mathbf{F}$ & $P$-value & $\eta^{2}$ \\
\hline RE post-test & 159.50 & 2 & 79.75 & 7.49 & 0.002 & 0.26 \\
\hline VE post-test & 81.28 & 2 & 40.64 & 7.82 & 0.001 & 0.27 \\
\hline PC post-test & 354.51 & 2 & 177.26 & 8.13 & 0.001 & 0.29 \\
\hline
\end{tabular}

According to Table 4, the results of the radial error post-test were significant for the group type ( $F=7.49, \mathrm{df}=2, \mathrm{P} \leq 0.002)$. Based on the above results, the effect of the type of instructional language was 0.26 , so the type of instructional language affects the radial error. The results of the two-dimensional variance error post-test were significant for the type of the group $(\mathrm{F}=7.82, \mathrm{df}=$ $2, \mathrm{P} \leq 0.001)$. According to the above table, the effect of the type of instructional language was 0.27 , so the instructional language type also affected Two-Dimensional Variation Error. The 
results of the perceived choice post-test were significant considering the type of the group $(\mathrm{F}=$ $8.13, \mathrm{df}=2, \mathrm{P} \leq 0.001$ ); therefore, according to the above table, the effect of the type of instructional language is 0.29 , meaning that the type of instructional language has an impact on perceived choice. Moreover, the results of the Bonferroni post hoc test for all three variables showed that the autonomy-supportive instructional language type was significantly different from the other two types of instructional language.

\section{Discussion and Conclusion}

The purpose of this study was to investigate the effect of the instructional language type on perceived choice and learning of dart throwing skills. The results revealed that in all three groups (autonomy-supportive, controlling, and neutral) that were instructed using three different types of instructional language, the value of radial error and two-dimensional variance error decreased in the post-test, suggesting that all three types of instructional language affect the dart-throwing skill learning; however, the autonomy-supportive instructional language differs significantly from the other two types of instructional language.

This can be discussed in several ways. Firstly, according to the "Law of Practice", learning occurs as a function of practice and continues as long as the practice takes place (Edwards, 2010). Accordingly, the results of the present study indicated that learning and practicing the skills by the learners improved the performance and accuracy of the skill in all three groups. Second is the analogy of the learning of the three groups with three different types of instructional language. The results showed that learning a new motor skill (modified dart-throwing skill) was improved while instructions supported the subjects' autonomy as compared with the controlling and neutral groups' instructions. Also, in the post-test, the autonomysupportive group showed significantly more accuracy in throwing at the target compared to the control group. This finding confirms that learning improves when conditions of practice reinforce learners' need for autonomy and independence (as compared with when the subjects' autonomy is paid less attention). Lewthwaite \& Wulf's study (2012) also confirms these results (Lewthwaite \& Wulf, 2012). Although considerable evidence from numerous studies has shown that learning under practice conditions controlled by the learner makes more progress compared with when the conditions are controlled by others (Sanli et al., 2013), the benefits of learning under such circumstances have been discussed only in terms of strengthening their autonomy or motivation. However, in sociopsychological studies, research has been limited to identifying the intrinsic relationships among various variables without directly measuring the performance or learning (Sheldon \& Filak, 2008), whereas the researcher in the present study has assessed the impact of the instructional language type on learning.

Hooyman et al.'s study (2014) is also in line with the present research. In their research, researchers found that learning Bowling Cricket increased as training strengthened autonomy compared to control training. In their research, it was found that learning the bowling (cricket) skill 
increased when the instruction supported autonomy compared to when controlling-style instruction was provided (Hooyman et al., 2014). Also, in Reeve \& Tseng's study (2011), it was reported that participants in the autonomysupportive group and the neutral style group (compared with the control group) were significantly more emotionally involved (such as enjoyment, entertainment, curiosity, interest) than the controlling style group, which might be the cause of improvement in the learning of these groups. Furthermore, Reeve \& Tseng's study (2011) states that probably self-regulated efforts to control negative emotional reactions in the controlling-style group may have deviated the participants' attention capacity from the task, thus leading to less learning (compared to the autonomy-supportive group) (Reeve \& Tseng, 2011). Also, according to Deci and Ryan's (1981) theory of autonomy, satisfying the need for autonomy can explain the effect of the type of instructional language on the subjects' performance (Deci et al., 1981). According to this theory, the autonomy-supportive instructional language may have fulfilled the basic psychological need of subjects for autonomy and facilitated learning in the autonomy-supportive group (relative to the other two groups). Therefore, the training environment can be designed to provide different levels of reinforcement and support to meet these three basic needs that can in turn influence behavior.

Many studies have cited further, deeper, and more useful information processing as a possible reason for the differences between self-control and obligatory skills instruction conditions (Patterson et al., 2011). In contrast, using motivational reasons, some studies have suggested that granting self-control to individuals in the practice setting may increase confidence in their ability to perform a task (Janelle et al., 1997). Accordingly, Su \& Reeve (2011) also describe the effort to reinforce internal sources of motivation and subsequently to reinforce the learner's autonomy as arousing pleasure in them, meeting their needs, or having them feel a sense of challenge or curiosity throughout the activity; therefore, in this study, the autonomy-supportive instructional language style may provide conditions for generating interest in or satisfaction with practice by giving learners the choice while they practice, or by exercising force in the instruction of the controlling group provide the grounds for controlling negative emotional reactions. This, in turn, redistributes information resources for the task. As a result, as the individual pays less attention to the task, less learning in this group is likely achieved than in the autonomysupportive group (Su \& Reeve, 2011). Another reason for improvements in people's performance under conditions reinforcing autonomy may be that these conditions facilitate functional connectivity. Functional connectivity includes task-related neural connections observed in distinct brain regions in skilled performers (Bernardi et al., 2013). Shifting toward the neural networks necessary for successful performance and departure from the default mode network responsible for self-referential thinking (Buckner, 2012) is facilitated by the use of the salience network (Wulf \& Lewthwaite, 2016). In contrast, 
the learner's lack of autonomy in learning a skill restricts the shift to task-related functional networks or restricts goal-behavior pairing.

As for the next research variable, as Table 1 shows, the mean of "perceived choice" at the posttest was relatively higher in participants of the autonomy-supportive group than in the other two groups. The results of the study done by Wulf et al. (2017) indicated that task-related choice had the same benefits as a non-task-related choice (Wulf et al., 2018). Also, the findings of research about subsidiary choice (Lewthwaite et al., 2015; Wulf \& Lewthwaite, 2016) have shown that the benefits of having control in learners are not related to the content of the choice but rather to the opportunity of the choice and its motivational results before its implementation (Wulf \& Lewthwaite, 2016). Lemos et al.'s study (2017) also confirms the results of the above research (Lemos et al., 2017). The researchers argue that providing students with the right to choose, which was present in their research at the time of viewing a video depicting ballet position, reinforced their need for autonomy and signaled an opportunity for intrinsic reward and thus resulted in more effective learning compared to the lack of choice state (the control group) (Lemos et al., 2017). In general, the findings of the present research are in line with the results of the above studies. In addition, the above results are consistent with Wulf \& Lewthwaite's OPTIMAL Theory (2016) suggesting that giving autonomy to the learner facilitates the pairing of goals and behaviors. The pairing of the goal and behavior (activity) included establishing effective neural connections that facilitate performance and lead to better learning (Wulf \& Lewthwaite, 2016). In what follows, the results of Su and Reeve's study (2011) are cited to further discuss and elaborate on the research topic. These researchers suggest that different conditions can affect one's sense of autonomy: 1) establishing meaningful principles, 2) recognizing negative emotions, 3) trying to reinforce internal sources of motivation, and 4) using a non-controlling tone (Su \& Reeve, 2011); Therefore, given the results of Tables (3) and (4) and the extent of the effect of the test on radial error, two-dimensional variable error, and perceived choice, and according to the results of $\mathrm{Su}$ and Reeve's study (2011), it is possible that in the present study meaningful principles and explanations, such as why the activity is beneficial for the learner or why the task should be done, has not been clear for the learners. Furthermore, although no specific case of recognizing negative emotions in motor learning research has been reported, it is impossible to ignore the feeling of tiredness or fatigue that can occur in participants, especially in the obliged group (controlling type of instructional language). Thirdly, the present research may have not made sufficient effort to bring enjoyment to the participants during the task or the dart task may have not been pleasant to some of the participants. Consequently, taking into account each of the above factors, changes may occur in the participant's autonomy and ultimately in the extent of the testing effect. However, the results of this study and previous research indicate that suppressing learners' needs can reduce learning. However, these factors cannot be talked about with certainty. Therefore, there is a need for 
further research which will be able to obtain more reliable results to confirm the results of the present study by modifying the instructional language based on different instruction methods and evaluating different tasks. As mentioned earlier, three types of instruction using video were shown to participants in three groups. Accordingly, a limitation of this study is the difference in students' perceptions of the instructor's instructional language style in the dart's film, which can make a difference in establishing a sense of autonomy or obligation in learners. Whereas, in the real-world instructional environment, the instructor's use of facial and hand movements (body language) or giving feedback to learners during the instruction may create a greater sense of autonomy or obligation in the learner. Therefore, it is recommended that studies be conducted to compare the autonomy-supportive and controlling instructional languages in a real-world practice setting. It is also suggested that other studies also investigate the role of instructional language type on the learning of athletic skills through the "diligence" variable. Finally, sports instructors and coaches are advised that giving the choice, even when it is not much important, or when the skills and insights of the learner are unknown, is a useful solution for people seeking to learn motor skills.

\section{Acknowledgments}

Students of the Farhangian University of Shiraz are appreciated for their participation in this study.

\section{References}

1. Bernardi, G., Ricciardi, E., Sani, L., Gaglianese, A., Papasogli, A., Ceccarelli, R., Franzoni, F., Galetta, F., Santoro, G., \& Goebel, R. (2013). How skill expertise shapes the brain functional architecture: an fMRI study of visuo-spatial and motor processing in professional racing-car and naïve drivers. PloS one, 8(10), e 77764.

2. Buckner, R. L. (2012). The serendipitous discovery of the brain's default network. Neuroimage, 62(2), 1137-1145.

3. Chen, D., \& Singer, R. N. (1992). Self-regulation and cognitive strategies in sport participation. International Journal of Sport Psychology.

4. Chua, L.-K., Wulf, G., \& Lewthwaite, R. (2018). Onward and upward: Optimizing motor performance. Human Movement Science, 60, 107114.

5. De Muynck, G.-J., Vansteenkiste, M., Delrue, J., Aelterman, N., Haerens, L., \& Soenens, B. (2017). The effects of feedback valence and style on need satisfaction, self-talk, and perseverance among tennis players: An experimental study. Journal of sport and exercise psychology, 39(1), 67-80.

6. Deci, E. L., Schwartz, A. J., Sheinman, L., \& Ryan, R. M. (1981). An instrument to assess adults' orientations toward control versus autonomy with children: Reflections on intrinsic motivation and perceived competence. Journal of educational Psychology, 73(5), 642.

7. Edwards, W. H. (2010). Motor learning and control: From theory to practice. Cengage Learning.

8. Hancock, G. R., Butler, M. S., \& Fischman, M. G. (1995). On the problem of two-dimensional error scores: Measures and analyses of accuracy, bias, and consistency. Journal of motor behavior, 27(3), 241-250.

9. Hooyman, A., Wulf, G., \& Lewthwaite, R. (2014). Impacts of autonomy-supportive versus controlling instructional language on motor learning. Human Movement Science, 36, 190-198.

10. Iwatsuki, T., Abdollahipour, R., Psotta, R., Lewthwaite, R., \& Wulf, G. (2017). Autonomy facilitates repeated maximum force productions. Human Movement Science, 55, 264-268.

11. Janelle, C. M., Barba, D. A., Frehlich, S. G., Tennant, L. K., \& Cauraugh, J. H. (1997). Maximizing performance feedback effectiveness through videotape replay and a self-controlled learning environment. Research quarterly for exercise and sport, 68(4), 269-279.

12. Kim, W., Chang, Y., Kim, J., Seo, J., Ryu, K., Lee, E., Woo, M., \& Janelle, C. M. (2014). An fMRI study of differences in brain activity among elite, expert, and novice archers at the moment of optimal 
aiming. Cognitive and Behavioral Neurology, 27(4), 173-182.

13. Kühn, A. A., Brücke, C., Hübl, J., Schneider, G.-H., Kupsch, A., Eusebio, A., Ashkan, K., Holland, P., Aziz, T., \& Vandenberghe, W. (2008). Motivation modulates motor-related feedback activity in the human basal ganglia. Current Biology, 18(15), R648-R650.

14. Leiker, A. M., Bruzi, A. T., Miller, M. W., Nelson, M., Wegman, R., \& Lohse, K. R. (2016). The effects of autonomous difficulty selection on engagement, motivation, and learning in a motioncontrolled video game task. Human Movement Science, 49, 326-335.

15. Lemos, A., Wulf, G., Lewthwaite, R., \& Chiviacowsky, S. (2017). Autonomy support enhances performance expectancies, positive affect, and motor learning. Psychology of Sport and Exercise, 31, 28-34.

16. Lewthwaite, R., Chiviacowsky, S., Drews, R., \& Wulf, G. (2015). Choose to move: The motivational impact of autonomy support on motor learning. Psychonomic bulletin \& review, 22(5), 1383-1388.

17. Lewthwaite, R., \& Wulf, G. (2012). 10 Motor learning through a motivational lens. Skill acquisition in sport: Research, theory and practice, 173.

18. Li, G., He, H., Huang, M., Zhang, X., Lu, J., Lai, Y., Luo, C., \& Yao, D. (2015). Identifying enhanced cortico-basal ganglia loops associated with prolonged dance training. Scientific reports, 5(1), 1-11.

19. Liu, D. L. J., Graham, S., \& Zorawski, M. (2008). Enhanced selective memory consolidation following post-learning pleasant and aversive arousal. Neurobiology of learning and memory, 89(1), 36-46.

20. McAuley, E., Wraith, S., \& Duncan, T. E. (1991). Self-Efficacy, Perceptions of Success, and Intrinsic Motivation for Exercise 1. Journal of applied social psychology, 21(2), 139-155.

21. Patterson, J. T., Carter, M., \& Sanli, E. (2011). Decreasing the proportion of self-control trials during the acquisition period does not compromise the learning advantages in a self-controlled context. Research quarterly for exercise and sport, 82(4), 624-633.

22. Reeve, J., \& Tseng, C.-M. (2011). Cortisol reactivity to a teacher's motivating style: The biology of being controlled versus supporting autonomy. Motivation and Emotion, 35(1), 63-74.

23. Sanli, E. A., Patterson, J. T., Bray, S. R., \& Lee, T. D. (2013). Understanding self-controlled motor learning protocols through the self-determination theory. Frontiers in psychology, 3, 611.
24. Schmader, T., Johns, M., \& Forbes, C. (2008). An integrated process model of stereotype threat effects on performance. Psychological review, 115(2), 336.

25. Sheldon, K. M., \& Filak, V. (2008). Manipulating autonomy, competence, and relatedness support in a game-learning context: New evidence that all three needs matter. British Journal of Social Psychology, 47(2), 267-283.

26. Su, Y.-L., \& Reeve, J. (2011). A meta-analysis of the effectiveness of intervention programs designed to support autonomy. Educational psychology review, 23(1), 159-188.

27. Wulf, G. (2007). Self-controlled practice enhances motor learning: implications for physiotherapy. Physiotherapy, 93(2), 96-101.

28. Wulf, G., Iwatsuki, T., Machin, B., Kellogg, J., Copeland, C., \& Lewthwaite, R. (2018). Lassoing skill through learner choice. Journal of motor behavior, 50(3), 285-292.

29. Wulf, G., \& Lewthwaite, R. (2016). Optimizing performance through intrinsic motivation and attention for learning: The OPTIMAL theory of motor learning. Psychonomic bulletin \& review, 23(5), 1382-1414. 